\title{
Egressos de um curso de Pedagogia: trajetórias formativas e profissionais*
}

Carla Patrícia Quintanilha Corrêa a

\section{Resumo}

Esse artigo apresenta os resultados de uma pesquisa que objetivou mapear e analisar a trajetória formativa e profissional dos egressos do Curso de Pedagogia do Instituto Superior de Educação Professor Aldo Muylaert (Isepam), instituição estadual sediada em Campos dos Goytacazes/RJ. Em 2018, realizou-se pesquisa de campo com 225 egressos ( $81 \%$ do total), que responderam a um formulário da Plataforma Google. A análise dos dados contou com o auxílio da Análise de Conteúdo, de Laurence Bardin. Os resultados revelaram que a inserção profissional dos participantes na área da Educação é de 75\%, enquanto $16 \%$ não atuam nesse setor e $9 \%$ estão desempregados. Os egressos que não atuam na área educacional indicaram que não o fazem por falta de oportunidade de trabalho. Sobre a formação continuada, mais da metade dos egressos já cursou ou cursa a especialização e dois egressos estão cursando o mestrado. A visão dos egressos sobre as oportunidades de formação continuada revelou dificuldades financeiras para custear a especialização privada e falta de tempo para se dedicar à pós-graduação pública.

Palavras-chave: Egressos. Curso de Pedagogia. Inserção Profissional. Formação Continuada.

\section{Introdução}

Pesquisas com egressos são conhecidas pelas dificuldades na localização e na sensibilização do público-alvo para colaboração, uma vez que muitos possuem uma rotina atarefada e nem sempre se motivam a participar (ANDRÉ, 2017; MOURA, 2017; RODRIGUES, 2016). Além disso, é razoável admitir dificuldades inerentes

\footnotetext{
* O presente artigo é resultado do estágio pós-doutoral da autora junto ao Programa de Pós-Graduação em Educação da Universidade Federal de Juiz de Fora, a quem expresso meus sinceros agradecimentos e em especial à Supervisora Prof ${ }^{a}$ Dra $^{a}$ Maria da Assunção Calderano.

a Instituto Superior de Educação Professor Aldo Muylaert, Rio de Janeiro, RJ, Brasil.
}

Recebido em: 18 mai. 2019

Aceito em: 15 jun. 2021 
ao processo de localizar egressos, considerando as possíveis mudanças de seus endereços e meios de contato. Raramente as instituições em que estudaram têm acesso a tais dados atualizados.

Esse artigo apresenta os resultados de uma pesquisa realizada em 2018 com egressos do Curso de Pedagogia do Instituto Superior de Educação Professor Aldo Muylaert (Isepam), uma instituição estadual que atende desde a Educação Infantil até o Ensino Superior, situada em Campos dos Goytacazes/RJ. Mesmo em face às dificuldades esperadas nas pesquisas com egressos, esse estudo contou com a participação de $81 \%$ do total de egressos do curso, que responderam a um formulário online enviado por e-mail. $\mathrm{O}$ fato da pesquisadora ser professora do curso de pedagogia do Isepam, tendo lecionado para vários dos egressos que aceitaram contribuir com o estudo, pode ter constituído fator auxiliador na devolução de formulários respondidos (ANDRÉ, 2017).

O objetivo do estudo foi mapear e analisar a trajetória formativa e profissional dos participantes. A trajetória formativa diz respeito ao percurso acadêmico dos egressos, a fim de conhecer o que já foi cursado em termos de pós-graduação ou se há essa intenção, mas ainda não houve oportunidade. A trajetória profissional refere-se à atuação na área educacional, seja na esfera de aprovação em concurso público, seleção em contrato temporário na rede pública ou obtenção de uma vaga na rede privada de ensino, verificando também as possíveis desistências de atuação na Educação e a migração para outras profissões.

A fim de refletir sobre os resultados encontrados, esse texto está organizado da seguinte forma: primeiramente, são discutidos alguns estudos que também abordam a problemática dos egressos dos cursos de licenciatura. Em seguida, são apresentadas algumas informações sobre o Isepam e seu curso de pedagogia, contexto da pesquisa realizada. Finalmente, parte dos dados angariados no estudo são analisados e algumas considerações finais acerca da temática proposta são levantadas.

\section{Os egressos dos cursos de Licenciatura}

Em se tratando de pesquisa no campo educacional, torna-se importante pesquisar os egressos dos cursos de licenciatura com o intuito de descortinar o que vem após a sua formação profissional. Quais caminhos foram percorridos e por que esses e não outros? Foi válido todo o esforço para apreender os conhecimentos básicos em relação à profissão ou o melhor é buscar outra área de atuação? Por que permanecer ou sair da docência? Continuar estudando é necessário, mas é possível? 
Dentre as pesquisas que têm sido desenvolvidas enfocando os egressos dos cursos de licenciatura e de programas educacionais voltados à formação docente, destacam-se algumas que se aproximam da temática desse estudo. André (2017) investigou o processo de iniciação à docência de egressos de três programas educacionais: o Programa Institucional de Bolsa de Iniciação à Docência (Pibid), em âmbito federal; o Bolsa Alfabetização, relativo ao governo do estado de São Paulo; e o Programa de Residência Pedagógica da Universidade Federal de São Paulo (Unifesp). Seus resultados apontaram que, dos 1.237 egressos participantes da pesquisa, $67 \%$ estão atuando na docência e $60 \%$, na rede pública. Sobre os egressos que não estavam atuando na área, os dados revelaram que $47 \%$ estavam aguardando uma oportunidade, o que indica a intenção de prosseguir na Educação. Para a maioria dos egressos, ter participado de um programa de iniciação à docência facilitou o início do trabalho como professor.

Teixeira et al. (2014) investigaram o perfil e o destino ocupacional de egressos em ciências biológicas e concluíram que a maioria deles era do sexo feminino, havia cursado a licenciatura e atuava predominantemente na docência, com uma renda mensal de três a quatro salários mínimos. Marques (2017) pesquisou a inserção profissional de egressos da licenciatura em física do Instituto Federal de Educação, Ciência e Tecnologia de São Paulo - Campus São Paulo. Os dados da pesquisa revelaram que $64 \%$ dos egressos atuavam como professores. Os desafios relativos à docência apontados pelos participantes são de ordem pessoal, como a timidez; interpessoal, nos relacionamentos travados e institucional, revelados na falta de condições materiais nas escolas, excesso de regulação externa, perda da autonomia profissional, sendo que esse último desafio se destacou em relação aos demais. Lima e Duarte (2014) voltaram sua atenção à formação continuada de egressos do curso de licenciatura em matemática do Instituto Federal de Educação, Ciência e Tecnologia do Ceará (IFCE), Campus de Cedro. Os resultados apontaram que os participantes do estudo atribuem importância à formação continuada, uma vez que o professor, como sujeito inacabado que é, necessita continuar aprimorando a sua prática.

Especificamente sobre os egressos do curso de pedagogia, foco do nosso estudo, Gonçalves et al. (2017) investigaram os egressos do curso de pedagogia da Universidade Federal de Ouro Preto (Ufop), no que tange à sua inserção no mercado de trabalho. Os resultados do estudo apontaram que a maioria dos egressos está inserida no mercado de trabalho $(75,7 \%)$, sendo que $72,9 \%$ atuam na área educacional e 51,4\%, em instituições da rede pública. Lucindo et al. (2018) pesquisaram a avaliação dos egressos do mesmo curso de pedagogia, sobre a formação que tiveram. Respondendo a um questionário online, 145 egressos participaram do estudo. Para 70 deles, o projeto pedagógico, o 
currículo e as condições materiais da instituição alcançaram o conceito "bom". Lacunas foram apontadas no que tange à formação para atuar na Educação Infantil e na gestão, indicando a necessidade de reformulação curricular na ótica dos egressos.

Haas e Ribeiro (2016) investigaram, junto a egressos de um curso de pedagogia, o que é ser pedagogo para os participantes. Dos 46 egressos que responderam a um questionário online, 14 assinalaram que estão aptos a trabalhar em todas as funções possíveis a um pedagogo, isto é, não só na docência. Para 9, dos 46 participantes, o curso trouxe preparação apenas para a atuação na Educação Infantil, enquanto 11 egressos declararam que estão preparados para trabalhar na Educação Infantil e no Ensino Fundamental. Os resultados do estudo apontam para o reconhecimento da qualidade do curso pelos egressos, mas lacunas também foram apontadas na vivência de uma perspectiva interdisciplinar e na frágil formação para a gestão.

Moraes et al. (2018) sondaram a trajetória de egressos do curso de pedagogia do Instituto Nacional de Educação de Surdos. A análise dos dados evidenciou que mais de $90 \%$ deles conceituaram como "bom" ou "ótimo" o seu curso de graduação, e a análise de conteúdo mostrou que a categoria de maior insatisfação dos participantes foi "currículo".

Dentre os estudos apresentados, o de Gonçalves et al. (2017) adquire especial relevância no panorama dos trabalhos sobre egressos do curso de pedagogia, por também se tratar da sua inserção profissional. Seus dados indicam que o curso de pedagogia, dentro dos limites empíricos propostos, tem conseguido proporcionar a inserção profissional tão almejada pelos egressos. A atuação de boa parte deles na rede pública de ensino aponta para o fortalecimento da escola pública, que recebe a maioria da população e tem sofrido intensamente com a falta de investimento e a descontinuidade de políticas educacionais (LIBÂNEO, 2016).

\section{O curso de Pedagogia do Isepam}

O estudo proposto está diretamente ligado ao Isepam, instituição educacional pública estadual, pertencente à Fundação de Apoio à Escola Técnica (Faetec), situada em Campos dos Goytacazes/RJ. De acordo com o Plano de Desenvolvimento Institucional (PDI) Isepam Faetec (2012-2016), o Isepam teve sua gênese no ano de 1954, quando era chamado de Instituto de Educação de Campos (IEC). Contando com uma área de $25.000 \mathrm{~m}^{2}$, o IEC ocupava, segundo Crespo (2009, p. 67), "uma posição estratégica, por ser ponto obrigatório de passagem para distritos circunvizinhos, zona litorânea e baixada campista". 
Ao IEC foi dada a missão de reunir três escolas - Jardim de Infância, Grupo Escolar Saldanha da Gama e Instituto de Educação - objetivando assumir a formação de professores na cidade, por meio do curso normal que oferecia, oportunizando o contato dos futuros professores com as crianças que também estudavam nas dependências do Instituto (CRESPO, 2009). Os anos iniciais do IEC não foram fáceis, de acordo com autor (2009). O Instituto foi instalado onde, desde 1947, já havia o Grupo Escolar Saldanha da Gama, uma escola primária pública, que, apesar de ocupar uma localização estratégica na cidade, estava situada em um bairro periférico. Somou-se a isso o fato de o curso normal ter sido transferido para o IEC, pois antes funcionava no Liceu de Humanidades de Campos, ${ }^{1}$ e, por isso, desfrutava do status de pertencer a um solar tradicional campista. A transferência, a princípio, não agradou aos alunos do curso, que se viram obrigados a deixar uma instituição prestigiada na cidade para estudar em um bairro periférico e em uma instituição recém-inaugurada.

De acordo com Crespo (2009), com o auxílio de festas organizadas pela direção do IEC, o desconforto inicial deu lugar à integração de todos os participantes. Na primeira década de funcionamento, o IEC consolidou-se como polo sócio educacional do município, por meio da construção de uma cultura pedagógica própria. Ao longo dos anos de seu funcionamento, muitas mudanças aconteceram.

Em 1965, Crespo (2009) revela que o IEC passou a ser chamado de Instituto de Educação Prof. Aldo Muylaert (Iepam). De acordo com informações disponíveis no site do Instituto Brasileiro de Geografia e Estatística (IBGE) a instituição passou a ser chamada pelo nome do seu ex-diretor, o Professor Aldo Muylaert, que esteve na direção por longo período e foi um dos responsáveis pelo desenvolvimento educacional da região, sendo, por isso, homenageado com a mudança do nome da instituição.

Em 2001, segundo Crespo (2009), o Iepam foi transformado em Isepam, pois passou a oferecer também um curso superior, o normal superior. Esse fato marcou a saída do Isepam da Secretaria de Educação Estadual do Estado do Rio de Janeiro (Seeduc) para pertencer à Faetec, ligada à Secretaria de Estado de Ciência, Tecnologia e Desenvolvimento Social.

Paiva (2011) pesquisou a política de interiorização dos Institutos Superiores de Educação (ISE) no estado do Rio de Janeiro, pertencentes à Rede Faetec.

\footnotetext{
Para um aprofundamento no processo de consolidação da formação docente no município de Campos dos Goytacazes/RJ, sugerimos os estudos de Boynard (2006), Crespo e Lima (2011), Lopes e Martinez (2008) e Martinez e Boynard (2004).
} 
Contando com seis ISE à época da pesquisa - o do Rio de Janeiro (Iserj), o de Santo Antônio de Pádua; o de Itaperuna; o de Campos dos Goytacazes (Isepam); o de Bom Jesus do Itabapoana e o de Três Rios -, a rede levou cursos de graduação e de pós-graduação lato sensu a municípios com escassa oferta nessas áreas.

Os ISE estudados revelaram ocupar elevado lugar social nos municípios do interior fluminense, mas carecem de uma política indutora de desenvolvimento regional que sustente a interiorização porquanto se configuram como uma medida isolada da política educacional do estado do Rio de Janeiro. Isso seria contornado, segundo Paiva (2011), por meio de uma política mais integrada entre as instituições estaduais, que juntasse esforços em prol da interiorização do Ensino Superior.

Paiva (2011, p. 265) conclui que “[...] a interiorização do Ensino Superior público fluminense por meio dos ISE não atende às reais necessidades do povo fluminense, mas, onde eles existem, são celebrados por serem, em alguns casos, a única opção acessível". A partir desses dados, destaca-se a defesa do acesso ao Ensino Superior público e de qualidade para todos como responsabilidade do poder público. Além disso, considerase, junto com Paiva (2011), que o ensino técnico e tecnológico pode ser uma opção para o cidadão, mas não a única possível. Por isso, é compromisso do poder público e de suas instituições estudarem as formas mais viáveis de garantir a acessibilidade de todos ao Ensino Superior gratuito e de qualidade. Nesse sentido, é importante indicar que o Isepam pode contribuir com o processo de expansão da interiorização, o que é indicado no presente artigo voltado à análise da trajetória formativa e profissional dos egressos do seu curso de licenciatura em pedagogia.

O curso de licenciatura em pedagogia do Isepam teve início em 2009, ao substituir o curso normal superior. O Isepam passou a oferecer, além das turmas de Educação Infantil, de Ensino Fundamental e de Ensino Médio, o curso normal em nível médio e o curso de licenciatura em pedagogia. Dessa forma, o Ensino Superior do Isepam compartilhava o espaço institucional com o Colégio de Aplicação (CAP), composto, segundo o Regimento Interno do Isepam (2012), pelos cursos de Educação Infantil, de Ensino Fundamental, de Ensino Médio, de Educação Profissional Técnica de Nível Médio, do Normal em Nível Médio e de Educação de Jovens e Adultos.

Segundo Soares (2015), esse processo de substituição do curso normal superior pelo curso de licenciatura em pedagogia foi marcado pelo descontentamento dos alunos do curso normal superior, que se consideravam preteridos em relação aos do curso de pedagogia. Havia uma sinalização da Faetec de que os alunos do primeiro curso seriam transferidos ao novo ofertado, o que não se concretizou. 
De acordo com o Projeto Pedagógico do Curso de Graduação em Pedagogia Licenciatura (2014), o Parecer n ${ }^{\circ}$ 110/2010 (RIO DE JANEIRO, 2010), credenciou o Isepam e autorizou o curso de pedagogia. Conforme o art. 61 do Regimento Interno do Isepam (2012), o curso de licenciatura em pedagogia é ministrado na modalidade presencial, sendo, portanto, obrigatória a frequência mínima de $75 \%$, independentemente dos demais resultados obtidos pelo cursista (art. 188).

Consta no Projeto Pedagógico do Curso de Graduação em Pedagogia - Licenciatura (ISEPAM, 2014), na concepção do curso, que o lugar do estágio pressupõe a unidade teoria e prática, na medida em que possibilita ao licenciando aproximarse da realidade em que atuará. Há uma particularidade em relação ao estágio do curso de pedagogia do Isepam: por ser um CAP, a instituição possui o campo de estágio necessário ao licenciando.

O Projeto Pedagógico do Curso de Graduação em Pedagogia - Licenciatura (2014) destaca, como um projeto desenvolvido na instituição, o Pibid. Voltado à valorização do magistério e ao incentivo da formação inicial de professores, o Pibid é um programa do governo federal executado no âmbito da Coordenação de Aperfeiçoamento de Pessoal de Nível Superior (Capes). Foi criado em 2007 e, até 2017, funcionou proporcionando a licenciandos a experiência de vivenciar o cotidiano escolar, ao desenvolverem atividades pedagógicas em uma escola de Educação Básica, acompanhados por um professor do seu curso de licenciatura, o coordenador de área, e outro professor da escola, o supervisor ${ }^{2}$. A partir de 2018, o programa passou a funcionar com outro formato, abrangendo apenas licenciandos da primeira metade do curso, uma vez que, para os licenciandos da parte final da licenciatura, outro programa do governo federal foi criado, o Programa Residência Pedagógica.

\section{A pesquisa com os egressos do curso de Pedagogia do Isepam}

A fim de atingir o objetivo proposto na pesquisa - mapear e analisar a trajetória formativa e profissional dos egressos do curso de pedagogia do Isepam solicitou-se à direção da instituição a liberação dos nomes dos egressos do curso. A solicitação foi encaminhada à Diretoria do Ensino Superior da Faetec, que autorizou a realização do trabalho. Assim, segundo a secretaria do curso, desde seu

\footnotetext{
A Portaria Capes n 96/2013 regulava o Pibid até 2017. Disponível em: <https://www.capes.gov.br/images/ stories/download/legislacao/Portaria_096_18jul13_AprovaRegulamentoPIBID.pdf>. Acesso em: 11 jul. 2018. Em 2018, o Edital Capes n 07/2018 apresenta o novo formato do programa. Disponível em: <http://www. capes.gov.br/images/stories/download/editais/27032018-Edital-7-Pibid-Alteracao-II.pdf>. Acesso em: 11 jul. 2018. Para mais informações, sugerimos os trabalhos de André (2012), Corrêa (2017) e Gatti et al. (2014).
} 
início, em 2009, até o momento da solicitação, o curso de pedagogia do Isepam contava com 282 licenciados que já haviam colado grau, pois não apresentavam pendências junto à instituição. A partir daí, a pesquisadora iniciou o processo de localização e de contato com os egressos para convidá-los a preencher um questionário online enviado por e-mail.

Nesse processo, foram utilizadas variadas formas de comunicação, tais como ligações telefônicas, envio de e-mails, mensagens de celular, do aplicativo WhatsApp e da rede social Facebook. Como a pesquisadora já havia sido professora de muitos egressos, seus contatos já estavam disponíveis em diversos formatos que foram sendo utilizados para convidá-los a participar, com destaque para a rede social Facebook, que permitiu a localização de muitos dos egressos que concordaram cooperar. Contudo, sem a colaboração dos próprios egressos, a pesquisa seria muito dificultada, pois os que aceitavam o convite, muitas vezes, auxiliavam localizando e convidando seus colegas de curso. Outros professores do curso e funcionários da instituição também foram acionados, contribuindo na localização dos egressos.

Tendo em vista esse esforço coletivo, chegou-se a $81 \%$ de devolução dos formulários. Como estudos envolvendo egressos geralmente enfrentam dificuldades com o retorno dos instrumentos de pesquisa, o alcance da marca indicada nesse estudo pode ser atribuído ao envolvimento dos próprios egressos auxiliando a pesquisadora. Analogamente, no estudo de André (2017, p. 10), apresentado anteriormente, "descobriu-se que [...] as respostas eram maiores nos casos em que os pesquisadores tinham tido contato com os ex pibidianos, e o retorno mais lento e difícil quando não havia esse contato pessoal".

Dos 282 nomes emitidos pela secretaria do curso, foram selecionados três egressos para a etapa de pré-teste, que auxiliou na busca por melhorar a compreensão acerca das perguntas do formulário. Assim, o e-mail contendo o formulário online final foi enviado para 244 egressos e obteve-se a devolução de 242 formulários. Desses, 17 foram descartados porque 6 foram enviados em branco, $10 \mathrm{em}$ duplicidade $\mathrm{e}$ 1 foi enviado pela pesquisadora como teste do sistema. Portanto, ao todo, foram recebidos 225 formulários válidos ( $81 \%$ dos egressos).

É importante ressaltar que o questionário só foi enviado para os egressos que consentiram participar da pesquisa. Vários convites foram enviados pelo recurso Messenger da rede social Facebook, que permite ver se a mensagem foi visualizada pelo destinatário. Algumas vezes, o egresso visualizou e não respondeu, mas, muitas vezes, a mensagem não foi visualizada, o que indica que alguns egressos não ficaram cientes do estudo. O processo de envio dos formulários foi realizado no ano de 2018, totalizando 30 dias. 
A elaboração do formulário enviado aos egressos se deu na plataforma Formulários Google (Google Docs), ferramenta do Google que permite a criação, envio, coleta e organização de uma pequena ou grande quantidade de informações. A escolha do formulário online foi motivada pelo quantitativo significativo de egressos a alcançar e o tempo estipulado para a pesquisa.

Considerou-se, a partir de Velho (1999), que a familiaridade da pesquisadora com o contexto investigado pode trazer vantagens, mas havia ciência do necessário processo de "estranhar o familiar", como parte importante dessa investigação. Além das contribuições de Velho (1999) ao processo de tratamento dos dados, outra contribuição fundamental para esse estudo veio da Análise de Conteúdo (BARDIN, 1977), uma vez que o formulário continha questões abertas, além das fechadas e de múltipla escolha, totalizando 40 questões.

\section{A trajetória formativa e profissional dos egressos}

Dos 225 participantes do estudo, 218 eram mulheres e 7 eram homens. Essa diferença significativa no quantitativo de homens e mulheres cursando pedagogia é conhecida nas pesquisas da área, indicando que a docência na Educação Infantil e nos anos iniciais do Ensino Fundamental é majoritariamente feminina (OLIVEIRA, 2013).

Após a conclusão do curso de pedagogia do Isepam, 22 participantes optaram por fazer outro curso de graduação. Desses, 17 escolheram outra licenciatura, ao passo que 5 decidiram-se por cursos de bacharelado.

Mais da metade dos respondentes - 115 - já cursou ou está cursando uma pósgraduação em nível de especialização. Outros 103 não cursaram nem estão cursando e 7 não responderam a essa questão. Somente 2 egressos informaram que estão cursando o mestrado. Portanto, nenhum egresso cursou, ou está cursando, o doutorado.

O interesse dos egressos em termos de continuidade dos estudos em nível de especialização, em sua maioria, praticamente empatou entre os que se dedicaram à área psicopedagógica (42) e os que escolheram a área pedagógica (41), que envolve gestão, supervisão, administração, orientação e inspeção escolar. Houve ainda 13 menções à área da religião, que engloba estudos nas ciências da religião ou em ensino religioso; 10 sobre a área da docência; 10 sobre a área da Educação Especial, evolvendo cursos voltados a Libras, Braile etc.; 7 na 
área das neurociências; 7 na área empresarial, 2 na área das tecnologias, 2 na área das ciências sociais, enquanto 6 egressos não especificaram seus cursos de especialização.

Quanto aos egressos que não cursaram, ou não estão cursando, a pós-graduação em nível de especialização - 103 respondentes - a falta de recursos financeiros é a principal causa para não continuarem seus estudos, com 30 menções. Isso porque, em Campos dos Goytacazes/RJ, são poucas as opções de cursos de especialização públicos voltados à área educacional. Essa é uma das razões por que muitos egressos optam pelos cursos a distância provenientes da iniciativa privada. Um egresso declarou: "Ainda não cursei, pois estava sem emprego e não tinha como pagar, mas pretendo iniciar no ano que vem, depois que minha situação financeira estiver normalizada" (Egresso 99).

Em $2^{\circ}$ lugar, aparece a falta de tempo, que impossibilita a dedicação aos estudos, com 27 menções. Em $3^{\circ}$, com 13 menções, vem a falta de oportunidade e, em $4^{\circ}$ lugar, questões familiares, como a criação de filhos, por exemplo, com 9 menções. Em $5^{\circ}$ lugar aparece a falta de motivação para dar continuidade aos estudos, com 6 menções. Essas foram as cinco categorias mais mencionadas pelos egressos (BARDIN, 1977).

A partir desses dados, constata-se que um quantitativo significativo dos participantes ainda não deu continuidade aos seus estudos (106 participantes). A análise dos dados revelou que a questão financeira foi a causa mais apontada para isso, o que lança luz na ausência de propostas públicas de pós-graduação para que os participantes tenham oportunidade de formação continuada. A questão do tempo também é preocupante, uma vez que aponta para as condições de trabalho dos profissionais de Educação (JACOMINI; PENNA, 2016; OLIVEIRA, 2013; 2016).

Nesse contexto, destaca-se, com base em Imbernón (2016), a necessária garantia de formação continuada na trajetória formativa dos egressos. As propostas que se mostram mais profícuas para a formação continuada dos professores são pensadas a partir de dentro das escolas (IMBERNÓN, 2016), valorizando as demandas reais dos professores, quer sejam iniciantes ou não. A troca coletiva no ambiente de trabalho tem se mostrado muito mais produtiva do que palestras esporádicas, totalmente desvinculadas das necessidades formativas do professorado.

Contudo, um ponto importante na formação continuada dos egressos também diz respeito à oportunidade de cursar a pós-graduação - especialização, mestrado e doutorado. Nesses espaços, o professor recebe auxílio para teorizar a sua 
prática e pesquisar sobre questões educacionais que envolvem o seu cotidiano profissional; pode participar de grupos de pesquisa, potencializando sua formação continuada; recebe incentivo para socializar seus achados em eventos que reúnem pesquisadores de diversas partes do país e de fora dele e conta com a orientação de um professor experiente em sua área de pesquisa (LÜDKE; RODRIGUES; PORTELLA, 2012; PORTELLA, 2008).

Os dados levantados nesse estudo apontam que o interesse na formação continuada está voltado à pós-graduação lato sensu em cursos de especialização e não à pós-graduação stricto sensu em cursos de mestrado e doutorado. Diante desse panorama, as universidades sediadas na cidade - Universidade Estadual do Norte Fluminense Darcy Ribeiro (UENF) e a Universidade Federal Fluminense (UFF) - não oferecem cursos de especialização na área educacional. Apenas o Instituto Federal Fluminense (IFF) oferece curso de especialização em educação, mas as vagas oferecidas são poucas diante da demanda existente. Como as vagas oferecidas são poucas e em horários que dificultam a jornada de trabalho, os egressos acabam por optar pela especialização cursada a distância, em instituições privadas.

Em relação à oferta de cursos de mestrado, as instituições de Ensino Superior públicas da cidade não oferecem mestrado em educação. Há cursos em áreas aproximadas, como por exemplo o Mestrado em Cognição e Linguagem na UENF e o Mestrado em Geografia na UFF, opções que podem não interessar aos egressos. Além disso, talvez, na visão dos egressos, a pós-graduação stricto sensu não seja um lugar ${ }^{3}$ possível para eles (BOURDIEU; CHAMPAGNE, 2008). Em outras palavras, é possível que haja uma separação nas suas disposições mentais entre o mundo do trabalho e o mundo acadêmico. E, nesse sentido, apropriar-se do lugar da academia seria algo difícil:

Acho mestrado algo muito difícil e puxado demais. Admiro e muito quem consegue fazer e terminar um mestrado. Eu não tenho cabeça para isso não. Vejo as pessoas se acabando por conta do mestrado. Pessoas ficando doentes física e psicologicamente por conta do mestrado. Tomara que um dia eu mude de ideia com relação a isso (Egresso 62).

Considero o mestrado muito difícil, exige muita dedicação (Egresso 198).

\footnotetext{
O conceito de lugar está sendo usado a partir de Bourdieu (2008), que o relaciona à localização ou posição que os agentes sociais ocupam no espaço social.
} 
Os depoimentos dos egressos destacam a dificuldade relacionada ao mestrado, que pode ser potencializada em se tratando do doutorado. Parece que os egressos atribuem valor simbólico à pós-graduação stricto sensu, mas não a ponto de elegê-la para estar no horizonte de possibilidades formativas de todos eles.

Em relação à trajetória profissional dos participantes do estudo, 75\% (169) responderam que estão atuando na Educação, enquanto $25 \%$ (56) responderam que não. A significativa maioria dos que atuam na Educação está na docência (125). Houve 13 menções ao cargo de pedagogo, 8 de direção escolar, 8 de auxiliar de turma, 4 de auxiliar de secretaria escolar, 2 de monitor do Programa Mais Educação, 2 de psicopedagogo, 3 de Atendimento Educacional Especializado (AEE), 1 de tutor no Ensino Superior a distância, 1 de tradutor/intérprete de Libras, 1 de secretária e 5 egressos não especificaram a sua área de atuação na Educação. Os achados de Gonçalves et al. (2017), apresentados anteriormente, também indicam que a maioria dos egressos permaneceu na área educacional.

Sobre a esfera de atuação dos egressos na Educação, 82 (49,0\%) são concursados nessa área, 55 (33,3\%) na rede privada, $27(15,2 \%)$ em contrato temporário na rede pública de ensino e $9(5,0 \%)$ que assinalaram a opção "outros", englobando 1 voluntário, 3 em cargos comissionados, 2 como RPA (Recibo de Pagamento Autônomo), 1 que atua por conta própria, 1 bolsista e 1 que não especificou. É importante ressaltar que 4 egressos atuantes na Educação não responderam a essa questão e que 1 mesmo egresso pode atuar na rede privada e na pública simultaneamente. Comparando os dados referentes aos participantes já concursados na área da Educação durante o curso de pedagogia - 26 cursistas - e os que foram aprovados em concurso após o curso - 82 egressos, verificou-se que houve um crescimento de 56 egressos aprovados em concurso público na área educacional.

Especificamente sobre os egressos que atuam na docência, prevalece a Educação Infantil (75), seguida de perto pelos anos iniciais do Ensino Fundamental (71). Em número muito menor, 14 egressos atuam como professores dos anos finais do Ensino Fundamental, outros 14 no Ensino Médio, 3 na EJA, 1 no Normal Médio, 1 no Ensino Superior e 1 no Ensino Profissionalizante. Um egresso respondeu que atua do $1^{\circ}$ ao $9^{\circ}$ ano do Ensino Fundamental e outro escreveu "orientação pedagógica”, o que, nesse caso, não se aplica.

Os egressos que não estão atuando na Educação justificaram sua posição (BARDIN, 1977). A principal razão gira em torno da ausência de oportunidades de trabalho nessa área (26 menções). Depois, aparecem a falta de experiência, com 7 menções, a questão do concurso (aguardando ser aprovados ou chamados), com 11 menções. 
Alguns desistiram da profissão, migrando para outras áreas (10 menções). Os exemplos abaixo ilustram essa situação ao apresentarem a resposta dos egressos à questão: "Se você não atua na Educação hoje, conte por quê".

Falta de oportunidades para as novas pedagogas (Egresso 74).

Porque os contratantes sempre solicitam experiência antes, e como eu não possuo, perco frequentemente oportunidades. Mesmo eu tendo realizado uma segunda graduação na área de Educação (Egresso 104).

Concurso Público 2012 em Campos dos Goytacazes para área da saúde. Concorrência menor (Egresso 181).

Porque não me identifico com sala de aula na Educação Infantil, e atuar como pedagoga hoje sem ser concursada e sem experiência fica difícil. Fiz um concurso público, passei, fiquei aguardando ser chamada e o prazo venceu e vários processos seletivos foram feitos e não fui convocada. Isso é muito desestimulador. Sou muito grata ao curso de pedagogia que me acrescentou muito como pessoa e profissionalmente, mas ainda não me realizei, por isso irei começar um novo curso acadêmico de direito. Em busca de novos conhecimentos e da incansável busca de realização profissional (Egresso 171).

Esses dados corroboram os dados provenientes do estudo de André (2017), apresentado anteriormente, que evidenciou a permanência na docência dos egressos das licenciaturas e os que não permaneceram alegaram a falta de oportunidades na área.

Além da ausência de oportunidades, outro dado preocupante diz respeito ao quantitativo de 20 egressos que se declararam desempregados, o que equivale a $9 \%$ do total dos participantes. Outros 33 egressos informaram a área em que estão trabalhando fora da Educação, enquanto 3 não especificaram em que área diferente da educacional atuam. Esse quantitativo de egressos desempregados e trabalhando em outras áreas, ainda que preocupante, mostrou-se menor do que o quantitativo encontrado por Almeida et al. (2020), ao investigarem 4 cursos de graduação da Faculdade UnB de Planaltina (FUP)/DF, com um alto número de egressos desempregados e com poucos trabalhando na sua área de formação.

A maioria dos egressos participantes - 83\% (186) - declarou que pretende trabalhar como professor nos próximos anos, enquanto $17 \%$ (38) descartam 
essa ideia. Esses dados indicadores da permanência na docência são muito promissores diante do atual quadro de baixa atratividade docente (CARDOSO; FIGUEIREDO; SOARES, 2016; LOUZANO et al., 2010; TARTUCE; NUNES; ALMEIDA, 2010).

Os egressos que não pretendem atuar como professor nos próximos anos registraram a área ou o cargo profissional que gostariam de exercer: pedagogo escolar (34), pedagogo empresarial (3), administração (2), psicopedagogo (2), psicólogo (1), promotor de justiça (1), contador (1), farmacêutico (1), consultor ambiental (1), voluntariado (1). A maioria desses respondentes (34) indicou sua preferência pela área da gestão escolar, coordenação pedagógica, supervisão escolar, orientação educacional, relacionadas à atuação do pedagogo escolar. Quatro egressos não especificaram a área pretendida em sua resposta. É importante considerar que ainda que esses egressos não pretendam exercer a docência futuramente, ainda assim desejam atuar no cotidiano escolar.

A intensão de não atuar como professor nos próximos anos pode estar associada às dificuldades inerentes ao trabalho cotidiano na sala de aula. Nesse aspecto, o egresso 207 pontuou: "Gosto da área de Educação, apenas não pretendo ficar muitos anos em sala de aula atuando como professora. Então penso em trabalhar como supervisora escolar no futuro". O desgaste no exercício profissional da docência pode ser a causa do interesse pelas demais áreas da pedagogia.

Os dados apresentados sobre a inserção profissional dos egressos, bem como de sua permanência na área, indicam uma significativa adesão à docência e às demais áreas da pedagogia voltadas ao contexto escolar. Dessa forma, os participantes parecem estar contribuindo para o desenvolvimento regional na área em que cursaram seu Ensino Superior (PAIVA, 2011).

\section{Considerações finais}

Esse artigo apresentou os resultados de um estudo realizado com egressos do curso de pedagogia do Isepam, objetivando conhecer sua trajetória formativa e profissional. Mesmo em face da reconhecida dificuldade na pesquisa com egressos, a marca de $81 \%$ alcançada nesse estudo foi extremamente significativa e atribuída à proximidade da pesquisadora com boa parte dos egressos participantes, uma vez que já haviam sido seus alunos durante o curso.

A trajetória formativa dos egressos revelou que mais da metade deles cursou a especialização como formação continuada. Um quantitativo muito reduzido está cursando o mestrado e nenhum egresso cursou, ou está cursando, o doutorado, 
o que sinaliza uma preocupante distância entre os egressos e a pós-graduação stricto sensu. Como a preferência dos egressos está no âmbito da especialização, as universidades sediadas na cidade - UENF e UFF - não contemplam essa modalidade. Apenas o IFF oferece curso de especialização em educação, mas as vagas oferecidas são poucas diante da demanda existente. Além disso, as condições objetivas de trabalho dos participantes, muitas vezes, não se ajustam aos horários oferecidos pelas instituições públicas que oferecem cursos de especialização, de mestrado e de doutorado. Um caminho mais viável a eles tem sido, então, a especialização a distância, oferecida pelas instituições privadas.

A pesquisa indicou que o curso de mestrado parece estar muito distante para os egressos, que preferem pensar sua pós-graduação em termos de especialização. Nesse sentido, a luta pela valorização do profissional da Educação não pode prescindir do cuidado com sua trajetória formativa, tendo como foco a possibilidade de desenvolver sua formação continuada de forma a ampliar os saberes já construídos e partilhados, inclusive em cursos públicos de especialização, de mestrado e de doutorado.

Já a trajetória profissional indicou que a maioria está atuando na área educacional, o que foi considerado muito promissor diante da difícil conjuntura enfrentada pelos professores cotidianamente. Outro fato a destacar diz respeito à aprovação dos egressos em concurso público na área educacional, o que claramente constitui fator importante na luta pela valorização do profissional da educação. Em tempos de baixa atratividade docente, os egressos participantes desse estudo parecem valorizar a atuação na área educacional, especialmente porque mencionaram, em sua maioria, que pretendem continuar nela nos próximos anos. 


\title{
Graduates of a Pedagogy Course: formative and professional trajectories
}

\begin{abstract}
This article presents the results of a research that aimed to map and analyze the formative and professional trajectory of the graduates of the Pedagogy Course of the Higher Education Institute Professor Aldo Muylaert (Isepam), a state institution based in Campos dos Goytacazes/RJ. In 2018, field research was carried out with 225 graduates $181 \%$ of the total), who answered a form from the Google Platform. Data analysis was supported by Content Analysis, by Laurence Bardin. The results showed that the professional insertion of the participants in the education area is $75 \%$, while $16 \%$ do not work in education and $9 \%$ are unemployed. The graduates who do not work in the educational area indicated that they do not do it due to lack of job opportunities. About continuing education, more than half of the graduates have already attended or attended specialization courses and two graduates are studying Master's degrees. The view of graduates about continuing education opportunities revealed financial difficulties to pay for private specialization courses and lack of time to enroll in public graduate courses.
\end{abstract}

Keywords: Egresses. Course of Pedagogy. Professional Insertion. Continuing Education.

\section{Graduados de un Curso de Pedagogía: trayectorias formativas y profesionales}

\section{Resumen}

Este artículo presenta los resultados de una investigación que tuvo como objetivo mapear y analizar la trayectoria formativa y profesional de los graduados del Curso de Pedagogía en el Instituto Superior de Educação Profesor Aldo Muylaert (Isepam), institución estatal con sede en Campos dos Goytacazes / RJ. En 2018 se realizó una encuesta de campo a 225 egresados (81\% del total), quienes respondieron un formulario de la Plataforma de Google. El análisis de datos fue apoyado por el Análisis de Contenido de Laurence Bardin. Los resultados revelaron que la inserción profesional de los participantes en el área de Educación es del 75\%, mientras que el 16\% no trabaja en este sector y el $9 \%$ está desempleado. Los graduados que no laboran en el área educativa indicaron que no lo hacen por falta de oportunidades laborales. En cuanto a la formación continua, más de la mitad de los graduados ya han cursado o están cursando el curso de Especialización y dos graduados están cursando actualmente un Máster. La visión de los graduados sobre las oportunidades de educación continua reveló dificultades financieras para financiar la especialización privada y falta de tiempo para dedicarlos a estudios públicos de posgrado.

Palabras clave: Graduados. Curso de Pedagogía. Inserción Profesional. Formación Continua. 


\section{Referências}

ALMEIDA, A. N. et al. Effectiveness of public university expansion in Brazil: comparison between the situation of graduated and dropout students. Ensaio: Avaliação e Políticas Públicas em Educação, Rio de Janeiro, v. 28, n. 107, p. 457-479, abr./jun. 2020. https://doi.org/10.1590/s0104-40362019002701864

ANDRÉ, M. Políticas e programas de apoio aos professores iniciantes no Brasil. Cadernos de Pesquisa, São Paulo, v. 42, n. 145, p. 112-129, jan./abr. 2012. https://doi.org/10.1590/S0100-15742012000100008

ANDRÉ, M. Inserção profissional de egressos de programas de iniciação à docência. In: REUNIÃO NACIONAL DA ANPED, 38., 2017, São Luís. Anais[...] Rio de Janeiro: Anped, 2017. p. 1-17.

BARDIN, L. Análise de conteúdo. Lisboa: Edições 70, 1977.

BOURDIEU, P.; CHAMPAGNE, P. Os excluídos do interior. In: BOURDIEU, P. (Coord.). A miséria do mundo. Petrópolis: Vozes, 2008. p. 481-486.

BOYNARD, M. A. A Escola Modelo anexa à Escola Normal de Campos: a experiência da "Seis de Março" (1916-1932). Dissertação (Mestrado em Educação) - Universidade Federal Fluminense, Niterói, 2006.

CARDOSO, M. C.; FIGUEIREDO, S. O.; SOARES, S. E. C. Atratividade da carreira docente na educação básica: fios de reflexões sobre o prazer e o sofrimento da professoralidade. Revista de Iniciação à Docência, v. 1, n. 1, p. 25-36, jan./jun. 2016. https://doi.org/10.22481/rid-uesb.v1i1.1590

CORRÊA, C. P. Q. A formação dos formadores do Programa Institucional de Bolsa de Iniciação à Docência (PIBID). Tese (Doutorado em Educação) Universidade Federal de Juiz de Fora, Juiz de Fora, 2017.

CRESPO, R. M. G. Politicas educacionais e magistério em terras fluminenses: itinerário sócio-histórico do Curso de Formação de Professores no Instituto de Educação de Campos, nas décadas de 1950-1960. Dissertação (Mestrado em Políticas Sociais) - Universidade Estadual do Norte Fluminense Darcy Ribeiro, Campos dos Goytacazes, 2009.

CRESPO, R. M. G.; LIMA, V. M. N. C. O. Patrimônio educativo da cultura escolar na historiografia do Instituto Superior de Educação Prof. Aldo Muylaert em Campos dos Goytacazes, 1959-2010. In: CONGRESSO BRASILEIRO DE HISTÓRIA DA EDUCAÇÃO, 6., 2011, Vitória. IVitória/ 
ES: Sociedade Brasileira de História da Educação, 2011. Tema: Invenção, tradição, escrita da história da educação no Brasil.

ESTADO DO RIO DE JANEIRO. Secretaria de Estado da Educação. Conselho Estadual de Educação. Parecer CEE No 110/2010. Autoriza o funcionamento do Curso de Licenciatura em Pedagogia e reconhece a adaptação do Projeto Curricular do Curso de Licenciatura de Normal Superior, nos termos da Resolução CNE/CP n ${ }^{\circ} 1 / 2006$, ministrado no Instituto Superior de Educação Professor Aldo Muylaert-ISEPAM, localizado na Av. Alair Ferreira, $n^{\circ}$ 37, Bairro Turf Club, Município de Campos de Goytacazes, RJ, mantido pela Fundação de Apoio à Escola Técnica - FAETEC. Disponível em: http://www.cee.rj.gov.br/pareceres/P_2010-110.pdf. Acesso em: 27 jan. 2018.

GATTI, B. A. et al. Um estudo avaliativo do Programa Institucional de Bolsa de Iniciação à Docência (PIBID). São Paulo: Fundação Caros Chagas, 2014. (Coleção Textos, v. 41).

GONÇALVES, A. P. et al. Egressos do Curso de Pedagogia da UFOP: a inserção no mercado de trabalho. In: EDUCERE - CONGRESSO NACIONAL DE EDUCAÇÃO, 13., 2017, Curitiba. Anais[...] Curitiba: PUC-PR. 2017. p. 15597-15608. Tema: Formação de Professores: contextos, sentidos e práticas

HAAS, C. M.; RIBEIRO, E. F. D. "Ser pedagogo" para alunos egressos de um curso de pedagogia: dialogando com a prática formativa. Revista de Estudos Aplicados em Educação, v. 1, n. 1, p. 30-48, jan./abr. 2016. https://doi. org/10.13037/rea-e.vol1n1.4254

IMBERNÓN, F. Qualidade do ensino e formação do professorado: uma mudança necessária. São Paulo: Cortez, 2016.

INSTITUTO BRASILEIRO DE GEOGRAFIA E ESTATÍSTICA - IBGE. Biblioteca. Catálogo. Disponível em: https://biblioteca.ibge.gov.br/bibliotecacatalogo.html?id=445111\&view=detalhes. Acesso em: 27 jan. 2018.

INSTITUTO SUPERIOR DE EDUCAÇÃO PROFESSOR ALDO MUYLAERT - ISEPAM. PDI ISEPAM FAETEC (2012-2016). Campos dos Goytacazes, [201?].

INSTITUTO SUPERIOR DE EDUCAÇÃO PROFESSOR ALDO MUYLAERT - ISEPAM. Projeto pedagógico do curso de graduação em pedagogia: licenciatura. Campos dos Goytacazes, 2014. 
INSTITUTO SUPERIOR DE EDUCAÇÃO PROFESSOR ALDO MUYLAERT - ISEPAM. Regimento Interno ISEPAM. Campos dos Goytacazes, 2012.

JACOMINI, M. A.; PENNA, M. G. O. Carreira docente e valorização do magistério: condições de trabalho e desenvolvimento profissional. ProPosições, Campinas, v. 27, n. 2, p. 171-202, maio/ago, 2016. https://doi. org/10.1590/1980-6248-2015-0022

LIBÂNEO, J. C. Políticas educacionais no Brasil: desfiguramento da escola e do conhecimento escolar. Cadernos de Pesquisa, São Paulo, v. 46, n. 159, p. 38-62, jan./mar. 2016. https://doi.org/10.1590/198053143572

LIMA, F. J.; DUARTE, M. I. S. A formação continuada do professor: sentidos e significados para os egressos do Curso de Licenciatura em Matemática do IFCE Campus de Cedro. Conexões Ciência e Tecnologia, Fortaleza, v. 8, n. 2, p. 16-26, jul. 2014. https://doi.org/10.21439/conexoes.v8i2.583

LOPES, S. C.; MARTINEZ, S. A. A emergência de escolas normais no Rio de Janeiro do século XIX: Escola Normal do Município da Corte e Escola Normal de Campos. Revista Brasileira de História da Educação, v. 7, n. 3(15), p. 53-77, set./dez. 2007.

LOUZANO, P. et al. Quem quer ser professor? Atratividade, seleção e formação docente no Brasil. Estudos em Avaliação Educacional, São Paulo, v. 21, n. 47, p. 543-568, set./dez. 2010.

LUCINDO, N. I. et al. Avaliação do Curso de Pedagogia da Universidade Federal de Ouro Preto: a ótica dos egressos. Revista Triângulo, Uberaba, v.11, n. 1, p. 74-86, jan./abr. 2018.

LÜDKE, M.; RODRIGUES, P. A. M.; PORTELLA, V. C. M. O mestrado como via de formação de professores da educação básica. Revista Brasileira de Pós-Graduação, Brasília, DF, v. 9, n. 16, p. 59-83, abr. 2012.

MARQUES, A. C. T. L. Inserção profissional dos egressos de um curso de Licenciatura em Física. Revista Electrónica de Enseñanza de las Ciencias, v. 16, $\mathrm{n}^{\mathrm{o}} 1$, p. 1-27, 2017.

MARTINEZ, S.; BOYNARD, M. A. Atrás da Casa-Grande: memória, gênero e espaço escolar da Escola Normal de Campos. In: CONGRESSO BRASILEIRO DE HISTÓRIA DA EDUCAÇÃO, 3., 2004, Curitiba. Curitiba: SBHE, 2004. v. 1, p. 1-20. Tema: Educação escolar em perspectiva histórica. 
MORAES, M. et al. Egressos: um olhar sobre as trajetórias de graduados em Pedagogia do Instituto Nacional de Educação de Surdos. Ensaio: Avaliação e Políticas Públicas em Educação, Rio de Janeiro, v. 26, n. 100, p. 1084-1107, jul./set. 2018. ttp://dx.doi.org/10.1590/s0104-40362018002601546

MOURA, J. Concepções sobre os Cursos de Licenciatura de Educação a Distância: o que dizem os egressos e os evadidos da Universidade Federal de Juiz de Fora. Dissertação (Mestrado em Educação) - Universidade Federal de Juiz de Fora, Juiz de Fora, 2017.

OLIVEIRA, D. A. As políticas de formação e a crise da profissionalização docente: por onde passa a valorização? Revista Educação em Questão, Natal, v. 46, n. 32, p. 51-74, maio/ago. 2013. https://doi.org/10.21680/19811802.2013v46n32ID5122

OLIVEIRA, D. A. Carreira e piso nacional salarial para os profissionais da educação básica. Revista Retratos da Escola, Brasília, DF, v. 10, n. 18, p. 121140, jan./jun. 2016. https://doi.org/10.22420/rde.v10i18.654

PAIVA, F. S. A política de interiorização dos Institutos Superiores de Educação no Rio de Janeiro: agentes, concepções e interesses em disputa. Tese (Doutorado em Educação) - Universidade Federal Fluminense, Niterói, 2011.

PORTELLA, V. C. M. Um olhar sobre o(s) sentido(s) do mestrado na formação continuada de professores do Colégio Pedro II. Revista Contemporânea de Educação, Rio de Janeiro, v. 3, n. 6, p. 296-315, 2008. https://doi.org/10.20500/rce.v3i6.1555

RODRIGUES, G. M. C. Desafios à formação e perspectivas profissionais de trabalhadores-estudantes e estudantes-trabalhadores do curso de pedagogia. Dissertação (Mestrado em Educação) - Pontifícia Universidade Católica de Goiás, Goiânia, 2016.

SOARES, J. P. P. O Curso de Licenciatura em Pedagogia no Instituto Superior de Educação Professor Aldo Muylaert- Campos-RJ. In: COLOQUIO INTENACIONAL EDUCACAO, CIDADANIA E EXCLUSAO - DIDATICA E AVALIACAO, 4., 2015, Rio de Janeiro. Anais[...] São Paulo: Realize, 2015. p. 11-111.

TARTUCE, G. L. B. P.; NUNES, M. M. R.; ALMEIDA, P. C. A. Alunos do ensino médio e atratividade da carreira docente no Brasil. Cadernos de 
Pesquisa, São Paulo, v. 40, n. 140, p. 445-477, maio/ago. 2010. https://doi. org/10.1590/S0100-15742010000200008

TEIXEIRA, D. E. et al. Perfil e destino ocupacional de egressos graduados em Ciências Biológicas nas modalidades a distância e presencial. Ensaio Pesquisa em Educação em Ciências, Belo Horizonte, v. 16, n. 1, p. 67-84, jan.-abr, 2014. https://doi.org/10.1590/1983-21172014160105

VELHO, G. Observando o familiar. In: VELHO, G. Individualismo e cultura . Rio de Janeiro: Zahar, 1999. p. 123-132.

\section{Informações sobre a autora}

Carla Patrícia Quintanilha Corrêa: Doutora em Educação pela Universidade Federal de Juiz de Fora. Pós-Doutorado em Educação pela mesma universidade. Professora do Curso de Licenciatura em Pedagogia do Instituto Superior de Educação Professor Aldo Muylaert. Contato: carlapqcorrea@hotmail.com

iD https://orcid.org/0000-0001-9934-8151 